\title{
POSSIBILIDADES DE ENTREVER A ÉTICA NA INFORMAÇÃO EMPRESARIAL
}

\author{
Francisco das Chagas de Souza
}

\section{Resumo}

Discute o sentido ou conteúdo que pode ter o tema ou noção "ética na informação empresarial", ao considerar que para sua compreensão torna-se necessário fazer e faz em síntese a discussão prévia das noções de "ética do empresário", "ética da empresa", "ética do mercado", "ética do cliente/consumidor de produtos e serviços" e "ética do gestor da informação".

\section{Palavras-chave}

Ética na informação empresarial; Ética da empresa; Ética do gestor da informação

\section{INTRODUÇÃO}

Na ordem do simbólico - fartamente utilizado para representar, com possibilidade também de adulterar, a concretude da realidade, especialmente quando se refere aos interesses do capital global, em sua rede de interdependências que envolvem no mesmo circuito, as grandes e opressoras empresas industriais, financeiras e de serviços mais globais que locais e as pequenas empresas oprimidas industriais, financeiras e de serviços, mais locais que globais - a palavra ética extravasa diferen- tes tipos de interpretação construídas pelo conteúdo ideológico advindo dos valores, crenças e sentimentos diferenciados de poder de quem expõe tais interpretações.

Se a idéia mais universal vinculada à palavra ética é a de uma busca incessante da felicidade do segundo sujeito da relação interpessoal, do interlocutor, pelo sujeito do discurso que constrói o interdiscurso em um diálogo, com a mesma dimensão da felicidade desejada pelo primeiro sujeito da relação interpessoal (ECO, 2000), portanto, se a ética é a plena igualdade inclusive de poderes, direitos e deveres entre as pessoas envolvidas em uma relação humana, 
seja ela qual for, não parece fora da realidade explícita falar de ética na informação empresarial?

De outro lado, a idéia de uma ética na informação empresarial teria que alcance? Incorporaria que conteúdos? Refletiria que valores? Comprometeria que instâncias? Demarcaria quais relações? Assumiria, enfim, quais responsabilidades?

O objetivo deste artigo é discutir o que constitui sentido conseqüente para um conceito tão abstrato quanto é o de ética (MOORE, 1998) em um campo que tem o sentido tão prático, imediatista e de interesse individualista (BOURDIEU, 1998; 2001) quanto é este que trata dos negócios e da aplicação da informação como instrumento para o alcance de lucro.

\section{ALCANCE ÉTICO DA INFORMAÇÃO EMPRESARIAL}

Em primeiro lugar a informação empresarial não constitui um acervo homogêneo. Ela está diversificada à razão diretamente proporcional das diferenças que demarcam as estruturas encontradas nas empresas que, menos ou mais verticais, ainda assim, têm, decisores, planejadores ou estrategistas e executores situados em diferentes posições definidas pelos objetivos específicos que devem alcançar para dar conseqüência à missão auto-atribuída pela organização como um todo.

Em segundo lugar a informação empresarial é produzida dentro de um contexto mais competitivo que cooperativo em que participam empresas do mesmo setor e de outros setores. Ela é dependente, minimamente, das formas e conteúdos das relações desenvolvidas entre empresas, setores produtivos, estado e clientela.
Em terceiro lugar a informação empresarial se constitui e evolui no tempo, sendo transformada e transformadora das relações e das práticas organizacionais, negócios, políticas do conjunto das sociedades nacionais ou da sociedade global.

Por essas e por outras perspectivas, a discussão da ética na informação empresarial só adquire qualidade quando precedida da discussão das éticas que a constituem, ou das éticas das pessoas ou setores que com ela se relacionam. Deste ponto de vista, se coloca como necessidade mínima, até preliminar, que se discuta as demais éticas das quais ela depende. Essa relação de dependência traz para o debate "a ética da empresa"; "a ética do mercado", "a ética do empresário" e "a ética do gestor da informação", e coloca como pergunta básica "o que tais sujeitos éticos assumem?” (CALAME, 2001).

Retomando, em Eco (2000), que a ética nasce a partir de uma consciência sobre a existência de um outro, um interlocutor, então se coloca como básico dar a e esperar do interlocutor respostas que correspondam ou expressem a consciência de valores associados à não-predação e sim à cooperação. No salve-se quem puder do mercado, em que palavras-chaves como competição, competitividade, competência, dentre outras, se estabelecem com peso de dogmas, é possível a prática dessa cooperação? No conjunto de ações que as empresas realizam na captação de clientela, que é outra palavra dogmática, com origem na cidade grega (COULANGES, s.d.), consistindo na subjugação e dominação de quem tem algum dinheiro para gastar mas não tem a necessária autonomia e liberdade de escolha, que dimensão ocupa a ética na informação empresarial? Considerando as formas de inserção nos mercados permitidas pelas novas tecnologias, em que o mercado passa a ser cada cliente, 
pois sobre ele passam a atuar sistematicamente todas as empresas, com ofertas de serviços e produtos (SANTOS, 2000) como pode ser interpretada a presença da ética na informação empresarial?

É por conta dessas perguntas que, para refletir sobre uma ética na informação empresarial, precisa-se começar a refletir sobre "a ética da empresa"; "a ética do mercado", "a ética do empresário", "a ética do cliente ou consumidor" e "a ética do gestor da informação", e "o que tais sujeitos éticos assumem?"

\section{A ÉTICA DA EMPRESA}

Como qualquer sujeito, a empresa tem um centro de pensamento, constituído pelas pessoas que a compõem sob uma liderança que, ao cabo de uma reflexão para a ação toma as decisões que se identificam como a decisão da empresa. Portanto, ao pensar, refletir para a ação e decidir rumos que garantem sua existência e continuidade, expectativa comum e natural de todo e qualquer sujeito vivo, a empresa necessita de algumas razões para ser ética e agir eticamente. Dentre tais razões, pode-se apontar (SOUZA, 2001) as seguintes: 1 - o ser empresa - significando a consciência de sua existência, num mundo real concreto em convivência com outras empresas e com a sua clientela e, portanto, capaz de assumir responsabilidades inerentes à natureza de ser empresa; 2 - o viver como empresa - significando a sua existência material, suas instalações, seus produtos, enfim a face visível de seu ser. O que pode ser percebido externamente pelos outros sujeitos com quem constitui relação; 3 - o conviver como empresa - significando a construção, manutenção e continuidade das relações com os outros sujeitos, empresas e clientes. Aqui, necessariamente, se define o futuro, com dois rumos: a) a convivência como luta pela hegemonia com a busca firme da eliminação dos concorrentes; ou b) a luta pelo crescimento conjunto com a valorização da cooperação setorial, em que pesa o sentido de multiplicação e não extinção. Aqui a atitude ponderada dos sujeitos, o equilíbrio nas relações e o reconhecimento do setor como mais forte que cada empresa se colocam como relevantes por criar e desenvolver a idéia da mutualidade; 4) o obrigar-se como empresa - significando por em relevância o respeito aos pactos, às alianças propostas aos outros sujeitos (empresas ou clientes individuais) e assumindo os encargos que 0 contexto social e humano requer como condição para a existência futura do próprio planeta.

Essas razões para ser ético levam a uma ética prática (SINGER, 1993), isto é, à efetivação das ações éticas. Na empresa essas ações éticas dependem de um estatuto ético, ou seja, de que a empresa explicite para si, seus membros, e a sociedade como um todo, os procedimentos ou regras que orientam seu funcionamento e as relações que mantém com o ambiente econômico, político, social, natural, cultural etc. Tais procedimentos ou regras se articulam a partir das seguintes linhas de conduta (SOUZA, 2001):

- Consciência de sua missão como parte de uma sociedade que tem como meta a continuidade da existência de todos os seus sujeitos;

- Liberdade de ação como condição para que toda a sociedade possa crescer sem constrangimentos;

- Autoridade como uso correto da liberdade voltada para a construção do consenso pela via do diálogo permanente;

- Sobrevivência material como decorren- 
te da prática da autoridade, ou seja, da habilidade de construir consensos que fortalecem a cooperação dos sujeitos;

- Convivência como resultado do uso correto da liberdade a qual assegura a autoridade adequada para a sobrevivência. Assim, convivem os que cooperam e constroem consensos com respeito a todos os sujeitos;

- Igualdade como decorrente da existência de um ambiente de equilíbrio, construído a partir do exercício pleno e correto da autoridade no ambiente da sociedade em volta;

- Fraternidade como prática de convivência entre sujeitos em uma sociedade de iguais, voltados para relações satisfatórias de convivência.

\section{A ÉTICA DO EMPRESÁRIO}

O empresário, de modo geral, toma a iniciativa de estabelecer um negócio por motivações várias, porém intermedia sua ação com uma mercadoria muito rara, designada como capital na forma de moeda ou expressável monetariamente. Seu objetivo principal é o de fazer essa mercadoria crescer, gerar dividendos e, se possível, multiplicar-se ao longo do tempo. Seu crescimento e multiplicação implicam em acrescentar à composição básica (ou matériaprima) do produto ou serviço que leva ao consumidor / cliente uma parcela de remuneração do seu trabalho e uma parcela de remuneração do emprego da mercadoria capital, remuneração esta designada como lucro. Sem esta última ação esta mercadoria, o capital, não crescerá e o empreendimento tende à estagnação ou a um possível fracasso. Na perspectiva da ética, o lucro então se coloca como a realização do princípio ético da Sobrevivência material da empresa e do empresário. Na medida em que o lucro não seja abusivo, o empresário estaria pondo em prática adequadamente o princípio de Consciência de sua missão; apoiado pelo princípio da Liberdade de ação e respaldado pelo princípio da Autoridade. Isto Ihe permitiria estar reforçando sua presença na sociedade na medida em que fosse hábil ou capaz de aplicar os princípios de Convivência, de Igualdade e de Fraternidade.

Aqui, porém, aparece um problema fundamental que é o de definir o que significa "lucro não abusivo" ou "lucro razoável". De outro lado, se o capital empregado para a geração de um produto ou serviço deve ser remunerado pelo consumidor/cliente não é justo ser colocada em questão a necessidade da negociação desta remuneração? Será que não há uma medida em que esta remuneração se torna uma expropriação dos recursos dos consumidores/clientes? Considerando que em geral os consumidores têm pouca possibilidade de controle dos custos das diversas partes que compõem o preço final de um produto ou serviço e lhes sobra, pela lógica de mercado, comparar preços, aumentando seus próprios custos na aquisição de um bem, não se configura na maioria das vezes um desvio intencional por parte do empresário de uma boa ética, digamos de uma "ética do razoável"?

Cabe aqui, então, observar que toda empresa tem dois âmbitos de ação: a) produzir com qualidade, competência, eficácia e a baixo custo; e b) submeter-se aos princípios éticos que são adotados pelo empresário. Tanto melhor socialmente quanto humanamente será a empresa quanto mais ao primeiro âmbito de ação forem acrescentados pelo empresário os princípios de uma "ética do razoável" no que tange à remuneração do capital investido. Caso o empresário adote uma má ética neste âm- 
bito, uma ética do mal, tanto maior são as chances desta empresa prejudicar sua própria sobrevivência. Primeiro, por causar prejuízos materiais aos consumidores; segundo, por predar os concorrentes no mercado; terceiro, porque, mesmo conquistando espaços monopolísticos, chegará a um estágio de exaustão determinado por alianças de clientes ou empresas lesadas.

Assim, ética da empresa e ética do empresário têm uma relação original na medida em que o caráter do segundo termina por ser determinante para a existência e permanência da primeira.

\section{A ÉTICA DO CLIENTE OU CONSUMIDOR}

Cliente ou consumidor é, em última instância, o sujeito social que participa no conjunto de relações estabelecidas num dado mercado de oferta de produtos e serviços, tendo a capacidade de remunerar produtos ou serviços em seus vários componentes: matéria-prima, trabalho e custo razoável de um capital envolvido no respectivo bem. Portanto, por princípio, todo consumidor ou cliente é parceiro da empresa e do empresário, se colocando como interlocutor na relação de mercado. Desse modo, os princípios éticos de Consciência; de Liberdade de ação; de Autoridade; de Sobrevivência material; de Convivência; de Igualdade e de Fraternidade orientam sua conduta. Contudo, a limitação de sua intervenção dentro das relações de mercado difere conforme o montante que pode comprar. Se consumidor individual ou coletivo; pessoa física ou pessoa jurídica; adquirente de pequeno ou de grande porte, sua participação se diferencia pelo poder de barganha ou negociação que pode ter.

Portanto, isso significa que, em geral, aos princípios éticos do cliente / consumidor - como parte mais exposta nas relações de mercado e sujeito a sofrer preços abusivos que Ihes expropriam riqueza, por um lado, $e$ por outro, sendo suporte para a existência e permanência das empresas -, se acrescenta como necessidade o senso de defesa. Este se traduz em cobrar do estado - poder constituído para administrar o interesse comum - regulação explícita das relações que reduzam ou eliminem os abusos que possa sofrer. Assim, leis de defesa de consumidor, obrigatoriedade de informação sobre a composição de produtos, exibição de prazos de validade, exibição de preços e tabelas de preços, dentre ou formas têm proliferado nos últimos anos. Isso determina, também, a adoção de mecanismos de proteção de grupo, sob a forma de associações de defesa de direitos, cooperativas de consumo, etc. a fim de barrar ou reduzir a ação das empresas e empresários que adotam a má ética que se exibe na busca do "lucro abusivo".

Pela amplitude que o senso de defesa vem tomando, é possível concluir-se que um percentual significativo de empresas e empresários adota um sério desvio dos princípios éticos e que provavelmente o princípio da sobrevivência material dos consumidores não esteja em suas primeiras cogitações.

\section{A ÉTICA DO GESTOR DA INFORMAÇÃO}

Segundo Cano (1998), o campo de atuação do gestor da informação se define como aquele em que a informação é caracterizada como "recurso institucional (como el diñero)", isto é, também uma mercadoria. Neste sentido, o gestor de informação é, por excelência aquele que vai atuar no ambiente em que se reconhece o valor econômico da informação, que é o ambiente empresarial. Em outros termos, o gestor da 
informação é o sujeito mesmo que trabalha no que Claria et al. (2000?) caracterizam como a função de agregar "información a la información para transformarla en conocimiento". Assim, o gestor da informação é um produtor e não apenas um intermediário desinteressado de um serviço. Sua ação é medida de um ponto-de-vista econômico, isto é, pela perspectiva da capacidade que dispõe para gerar menos ou mais lucro para a empresa. Assim, sua ética está umbilicalmente ligada à ética da empresa e do empresário, estando condicionada especialmente pelas atitudes do segundo.

De outro lado, como profissional, o gestor da informação segue uma ética profissional que lhe orienta a atuar no sentido de responder aos interesses do seu cliente imediato, no caso empresa e empresário. Como já foi visto, se o empresário e a empresa aplicam a boa ética empresarial, com a realização da "ética do razoável" quanto à conquista do justo lucro, do gestor da informação é esperado e desejável que contribua neste sentido em cumprimento de seu papel pois, por extensão, estará atendendo de modo sadio ao desenvolvimento da sociedade onde estão inseridos: ele, a empresa e o empresário. Mas se o empresário e a empresa praticam a má ética empresarial, com a usurpação da clientela através do "lucro abusivo", será que é honesto o gestor da informação contribuir para isso? Colaborando com a má fé do empresário e da empresa o gestor da informação, neste caso, estará sendo tão antiético quando os dois primeiros e sua ética estaria privada dos princípios de Boa consciência; de Liberdade profissional; de Autoridade profissional; e ele estaria colaborando para prejudicar os outros sujeitos da sociedade em relação aos princípios éticos ligados à adequada Sobrevivência material; Convivência; sem contar a elisão dos princípios éticos de Igualdade e de Fraternidade. 7 A ÉTICA DO MERCADO
As razões do mercado para ser ético e agir eticamente não são diferentes daquelas que orientam as linhas de conduta das empresas, dos empresários e dos gestores de informação. Por outro lado, o mercado é uma microsociedade que envolve "empresas", "empresários", "clientes" e todos os grupos profissionais que atuam nas empresas do quais se destaca neste artigo "o gestor da informação". Assim, o mercado pode ou não expressar concretamente que linhas de conduta vão predominar nas relações entre os sujeitos envolvidos.

Desse modo, cabe perguntar e averiguar como ocorrem nesta microsociedade as práticas éticas? Nesse âmbito, como se manifestam as missões ou papéis de cada sujeito envolvido? E, assim, é cabível interrogar qual o exercício possível da Consciência dos sujeitos; da Liberdade de ação dos sujeitos; da Autoridade dos sujeitos; da Sobrevivência material dos sujeitos; da Convivência entre os sujeitos; da Igualdade dos sujeitos; e da Fraternidade entre os sujeitos.

Pode-se afirmar que é a partir deste ponto que se coloca a discussão do sentido que pode ter uma discussão sobre a ética na informação empresarial, até porque a fórmula verbal expressa pela frase ao conter a contração "na" sugere a inerência da ética neste fator de produção que é a informação. Em outros termos, a discussão é de que um substrato da informação empresarial, uma parte de sua composição, além de toda a instrumentalidade que possa conter se revela como conteúdo ético. Isso coloca então, para reflexão, algumas questões, como por exemplo: É possível que a informação empresarial contenha uma ética? Em caso afirmativo, que ética seria esta? Que linhas de conduta a determinam? Quais sujeitos materialmente se beneficiam dela? Ela leva a uma fraternidade 
entre os sujeitos?

\section{8 ÉTICA NA INFORMAÇÃO EMPRESARIAL}

Em nível puramente abstrato, posso pensar que ao comprar um livro, por exemplo, um percentual do que pago é o custo ético? $\mathrm{O}$ mesmo em relação à assinatura de uma base de dados, ou a compra de um serviço de consultoria, ou a inscrição em um Congresso?

Analisando, estritamente, pelo tema "ética na informação empresarial" a resposta é sim, com um detalhe, dependendo do empresário e da empresa de quem se adquire o bem este percentual de custo paga a boa ética de forma justa ou pode corresponder a uma expropriação indevida de parcela do patrimônio do consumidor, na medida em que a informação empresarial que compõe o custo do dito bem seja produzida sob a orientação da "ética do razoável" ou do lucro abusivo.

Nestes termos, cada consumidor/cliente, especialmente dentre os que consomem produtos e serviços no nível das classes de renda média, no Brasil e demais países, detém exemplos que conferem alguma praticidade a esta reflexão, pois tais exemplos são produzidos e tomam como referência a existência de um onipresente discurso universalista, o discurso da globalização, ou seja, um discurso que tenta afirmar por meio de uma representação ideológica e simbólica a naturalização das leis econômicas que constroem um e emanam de um mercado mundial com a capacidade de regular a participação econômica dos sujeitos.

O dia-a-dia de todos os consumidores/clientes Ihes permite perceber que a maioria dos produtos e serviços de que ne- cessita têm preços virtualmente deslocados de uma sadia correlação entre custos de produção, gestão e remuneração do capital utilizado e, por isso, afastados dos princípios de uma boa ética empresarial. No contexto sócio-econômico brasileiro, pode-se, sem muito esforço, ver claramente, (e aí estão as Associações de Donas de Casas, os PROCONS, etc. cheios de casos para estudo) os abusos advindos de todas as origens e centralmente vinculados a uma busca desenfreada do lucro, acima de qualquer percentual razoável. Todos os setores, com particular agravamento após a política governamental de privatização de grandes empresas estatais, passaram a seguir a má ética em relação ao custo do capital que empregam. Desse modo, os preços das tarifas públicas, do combustível, das taxas bancárias, dos equipamentos diversos, dos programas de computador, dos fármacos, das tarifas de transportes de passageiros e de mercadorias, dos produtos alimentares, dentre tantos outros, têm se elevado muito acima da remuneração do trabalho pessoal da grande maioria dos consumidores/clientes a qual é a fonte de receita para a aquisição daqueles bens e serviços que constituem a sua necessidade.

Este distanciamento entre custos dos produtos e serviços e a capacidade de compra cuja queda é permanentemente sentida pela maioria das pessoas e demonstrada pela análise microeconômica, social e financeira, só se sustenta a partir de um elenco de informações mais macroeconômicas utilizadas pelas empresas que ignoram a existência concreta das pessoas que consomem. É por isso, então, que a análise social e política não têm se cansado de demonstrar nos últimos doze anos que há um fundo ideológico o qual, por ser avassalador em suas estratégias de comunicação, ao obscurecer a realidade pelo excesso de informação, tenta dizer-se portador de leis naturais, pois científicas: da ci- 
ência econômica (BOURDIEU, 1998; 2001). Desse ponto de vista, ao considerarmos que o empresário, a empresa e o gestor de informação compõem parte deste universo em que a linguagem dessa ciência econômica tende a ter maior importância que os princípios de uma boa ética, fica difícil de enxergar o sentido de uma ética na informação empresarial. Os exemplos concretos que possam ser trazidos ao debate, oriundos de quaisquer setores econômicos, tendem a mostrar que a natureza dos fundamentos éticos presentes na maior parte dos negócios tem o vício do deslocamento entre a capacidade de compra do consumidor e o desejo de lucro da empresa e do empresário. Portanto, nestes casos, já há um sentido prédefinido para o que pode ser tomado como o exercício de uma ética na informação empresarial da maior parte dos empresários e empresas, sem distinção de ramos ou setores de geração de produtos e/ou serviços. E esta, é provável, não se trata de uma ética da informação que construa o sentido de cooperação razoável e desejável entre consumidores/clientes e produtores de bens e serviços.

\section{CONSIDERAÇÕES FINAIS}

Seguramente, a ética na informação empresarial se situa como uma problemática, isto é, um conjunto de questões que, pelos aspectos que carrega, extrapola uma abordagem generalista da ética. Ela exige uma análise que recoloca a Filosofia como o pensar o mundo, recriar o mundo, pois nos termos em que hoje se apresenta confronta no mínimo os universos filosóficos construídos no ocidente nos últimos séculos. Na medida em que hoje a razão econômico-pragmatista Peirceana tende a se colocar como a razão do mundo e da existência ela destrói certos fundamentos da razão iluminista Kantiana do homem como senhor do mundo, posto que cada vez mais os gestores da economia desconhecem no homem consciente esse poder, na medida em que dizem submeter-se e submetem os povos aos ditatoriais fundamentos de uma economia liberal, por princípio um "salve-se quem puder".

Por fim, se a empresa, o empresário e o gestor da informação só tendem a responder e a atender a esse princípio pragmático centrado no lucro abusivo, como fica, o que significa, onde se aplica e como se aplica a ética na informação empresarial? Será possível que a informação empresarial contenha uma ética? Em caso afirmativo, que ética seria esta? Que linhas de conduta a determinariam? Nela existem sujeitos para além da empresa e do empresário? Quais sujeitos materialmente se beneficiam dela? Ela leva a uma fraternidade entre os sujeitos? A quais sujeitos?

\section{REFERÊNCIAS}

BOURDIEU, P. Contrafogos; táticas para 
enfrentar a invasão neoliberal. Rio de Janeiro: Jorge Zahar, 1998. 151 p.

BOURDIEU, P. Contrafogos; por um movimento social europeu. Rio de Janeiro: Jorge Zahar, 2001. 115 p.

CALAME, P. Missão possível: pensar o futuro do planeta. Itajaí, SC: Ed. Univali, 2001. $261 \mathrm{p}$.

CANO, V. De bibliotecario a gestor de información. ? Cambio de nombre o nuevas competencias? Disponível em http:// imdept.qmuc.ac.uk/imres/fulltxt/ txt_VC4.htm. Acesso em 31.08.01.

CLARIA, A. M. Centros de información: una nueva forma de gestión de la información para las empresas. Disponível em http:// abgra.sisbi.uba.ar/t15.htm. Acesso em 31.08.01.

COULANGES, F. de. A cidade antiga; estudos sobre o culto, o direito, as instituições da Grécia e de Roma - 1864. Rio de Janeiro: Ediouro, s.d.

ECO, U. Quando o outro entra em cena, nasce a ética. In: ECO, U.; MARTINI, C. M. Em que crêem os que não crêem? Rio de Janeiro: Record, 2000. p. 79-90.

MOORE, G. E. Principia ethica - 1903. São Paulo: Ícone, 1998. 304 p.

SANTOS, L. G. dos. Limites e rupturas na esfera da informação. Disponível em: http:/ /www.comciencia.br/reportagens/socinfo/ info16.htm. Acesso em 21.07.01. (Conferência apresentada na $52^{i}$ Reunião anual da SBPC, Brasília, 2000).

SINGER, P. Ética prática. São Paulo: Martins Fontes, 1993. $399 \mathrm{p}$.

SOUZA, F. das C. de. Ética e deontologia: textos para profissionais atuantes em bibliotecas. Itajaí, SC: Ed. Univali; Florianópolis: Ed. UFSC, 2001. 165 p. 


\section{Francisco das Chagas de Souza}

UFSC - Departamento de Ciência da Infor-

mação

Bibliotecário; Graduado em 1978 pela Universidade Federal do Ceará. Mestre em Biblioteconomia pela Universidade Federal de Minas Gerais em 1982. Doutor em Educação pela Universidade Metodista de Piracicaba em 1994. Desde 1983 é professor do Departamento de Ciência da Informação da Universidade Federal de Santa Catarina, em Florianópolis. Publicou vários livros na área.

chagas@ced.ufsc.br - souza@amja.org.br http://www.ced.ufsc.br/bibliote/dep/fcscv.htm

\section{Title}

Possibilities to comprehend the ethics in the enterprise information

\section{Abstract}

Discusses the sense (or content) that can assume the subject (or notion) of "etichs in enterprise information". For this analysis it is considered the need of discussing previously the notions of "ethics of the entrepreneur", "ethics of the enterprise", "ethics of the market", "ethics of the client/consumer of products and services" and "ethics of the information manager".

\section{Keywords}

Ethics in the Enterprise Information; Ethics in the Enterprise; Ethics of Information Management.

\section{Titulo}

Posibilidades de entrever la ética en la información empresarial

\section{Resumen}

Discute el sentido o contenido que puede tener el tema o noción "ética en la información empresarial", al considerar que para su comprensión tornase necesario hacer y haz en síntesis la discusión previa de las nociones de "ética del empresário", "ética de la empresa", "ética del mercado", "ética del cliente/consumidor de productos y servicios" y "ética del gestor de la información".

\section{Palabras-clave}

Ética en la Información Empresarial; Ética de la Empresa; Ética del Gestor de la Información

Artigo recebido em: 05/10/2001 